\title{
Myodermal flap for reconstruction of oral mucosa
}

Masataka Uehara, DDS, PhD,* Tsugio Inokuchi, DDS, PhD, $\dagger$ Hisazumi Ikeda, DDS, PhD, $\ddagger$ Joji Sekine, DDS, PhD, $\ddagger$ Takayoshi Tobita, DDS, PhD,* Seigo Ohba, DDS, PhD,* Akihiko Fujisawa, DDS, PhD,* Mihoko Nonaka DDS, PhD,* Izumi Asahina, DDS, PhD§

*Assistant Professor.

†Professor Emeritus

$\ddagger$ Lecturer

§Professor and chairman

Division of Regenerative Oral Surgery, Unit of Translational Medicine, Graduate School of Biomedical Sciences, Nagasaki University, Sakamoto, Nagasaki 852-8588, Japan

Address correspondence and reprint request to Dr. Masataka Uehara: Division of Oral \& Maxillofacial Surgical Reconstruction and Functional Restoration, Department of Developmental and Reconstructive Medicine, Nagasaki University Graduate School of Biomedical Sciences, 1-7-1 Sakamoto, Nagasaki 852-8588, Japan

Tel: +81-95-849-77094

Fax: +81-95-849-7705

e-mail: uehara@net.nagasaki-u.ac.jp 


\section{Abstract \\ Purpose}

Myocutaneous flaps were commonly used to repair the mucosal defect that results from ablative tumor surgery. However, skin is not a perfect substitute for the oral mucosa because it can lead to poor hygiene due to hair growth and desquamation. The myodermal flaps used for the reconstruction of mucosa in oncologic surgery of the oral cavity.

\section{Material and method}

Pectoralis major and platysma myodermal flaps were applied in 8 patients for the purpose of intraoral reconstruction in cancer surgery. The skin paddle of the flaps denuded by shaving the epithelial layer was transferred into the oral cavity to cover the mucosal defect.

\section{Result}

The flaps epithelialized secondarily without severe contraction.

\section{Conclusion}

The myodermal flap is a promising option for reconstruction of the oral mucosa. 


\section{Introduction}

Myocutaneous flaps were commonly used to repair the mucosal defect that results from ablative tumor surgery. However, skin is not a perfect substitute for the oral mucosa because it can lead to poor hygiene due to hair growth and desquamation. A muscle-only flap has been used for reconstruction of the oral cavity because it heals with secondary epithelialization, mimicking the oral mucosa ${ }^{1-3}$. However, cicatricial contraction remains an issue for the muscle-only flap ${ }^{4,5}$. In a previous study, we showed that fascial flaps heal with secondary epithelialization with mild contraction ${ }^{5}$. On the other hand, dermis contributes to the inhibition of wound contraction ${ }^{6}$. This paper describes myodermal flaps used for the reconstruction of mucosa in oncologic surgery of the oral cavity.

\section{Surgical technique}

Pectoralis major myodermal flap was used in 4 cases which had more than 
5cm diameter defect (cases 5, 6, 7, and 8). After denudement by shaving the epithelial layer using scalpel (Fig. 1), the pectoralis major myodermal flap was elevated (Fig. 2), and the flap was then applied to the defect (Fig.

3). The platysma myodermal flap was used in 4 cases (cases 1, 2, 3, and 4) for intraoral reconstruction. The advantages of this flap are the easy harvest and transplant to the defect. However, the blood supply to the skin paddle has been problematic. Because submental artery and vein plays an important role as feeder and venous drainage of the superiorly based design of the platysma flap, respectively ${ }^{7}$, it is of vital importance to maintain the patency of the facial artery and vein. Accordingly, platysma myodermal flap was selected for the cases whose facial artery and vein were preservable. After the denudement (Fig. 4), the flap was transferred into the defect of the oral cavity (Fig. 5).

\section{Cases}

A total of 8 patients, 2 males and 6 females, suffering from oral malignant 
tumor had their oral defects reconstructed with a myodermal flap (Table 1).

\section{Results}

The surface of the flaps was shown to be covered with granulation tissue at

1 week post-operatively. At 2 or 3 weeks post-operatively, stratified squamous epithelium completely covered the surface of the flaps without severe contraction (Figs. 6, 7). This prevented fixation of the tongue with resulting in neither masticatory disturbance nor dysphagia. The protheses were applied in all cases and they were well functional.

The postoperative biopsies showed surface epithelium, subjacent dermis. This indicates epithelializaton on the dermis of the flap. The dermis under the epithelium was occupied mostly by collagen fibers (Fig. 8).

\section{Discussion}

After the resection of oral cancer, prothese serves as a tool for functional 
rehabilitation. Because flap contraction makes it difficult to adjust the prothese on the flaps, vestibuloplasty and palatal mucosa grafts may be required ${ }^{1}$. In the previous study, we showed that the muscle-only flap heals with secondary epithelialization in the oral cavity, in a way similar to the mucosa. However, the flap matures to fibrous tissue with resultant severe contraction ${ }^{4,1}$. This biological behavior of the muscle-only flap may indicate the limitation of its applicability, suggesting that its best use is for mucosal defects in the osseous region ${ }^{1}$. In contrast with the muscle-only flap, we found that fascia flaps in the oral cavity heal with mild contraction ${ }^{5}$. This result suggests that different extracellular matrices consisting of bare flaps may play a determinant role in their secondary epithelialization ${ }^{5}$. Hill et al. ${ }^{8}$ have also reported that epithelial proliferation and histodifferentiation are influenced by the corresponding subepithelial connective tissue. Similarly to the fascia ${ }^{5}$, the dermis mainly consists of collagenous tissue ${ }^{9}$. Prior studies have suggested that the ability of the dermis to inhibit contraction depends on the preservation 
of the collagen matrix ${ }^{10,11}$. Accordingly, it may be valid to use a myodermal flap for reconstruction of the oral mucosa, and myodermal flap is likely to be reasonable to apply for soft tissue reconstruction in the alveolus regions.

Implant plays important role of oral rehabilitation after ablative tumor surgery. However, it is well known that implant placed on the flap frequently induce implantitis. The presence of a good tissue-implant interface is important for maintaining a healthy, stable environment. The seal between the implant and the oral epithelium is an especially important factor in determining a successful outcome. In the myocutaneous flap, it is possible for a pocket to form between the skin and the implant. On the other hand, the epithelialized myodermal flap may make close contact with the implant ${ }^{12}$ and create a good implant-tissue interface. However, defatting would be required for this flap to get thin and to adhere to alveolar bone for implant placement.

In conclusion, the myodermal flap is a promising option for 
reconstruction of the oral mucosa. 


\section{References}

1.Inokuchi T, Uehara M, Yoshida S, et al.: Use of the pectoralis major muscle-only flap for intraoral reconstruction. Asian J Oral Maxillofac Surg 9:27, 1997.

2. Johnson MA, Langdon JD: Is skin necessary for intraoral reconstruction with myocutaneous flaps? Br J Oral Maxillofac Surg 28:299, 1990.

3.Wolff KD, Dienemann D, Hoffmeister B: Intraoral defect coverage with muscle flaps. J Oral Maxillofac Surg 53:680, 1995.

4. Elshal EE, Inokuchi T, Sekine J, et al.: Experimental study of epithelialization of the muscle-only flap in the oral cavity. J Oral Maxillofac Surg 55:1423, 1997.

5. Elshal EE, Inokuchi T, Yoshida S, et al.: A comparative study of epithelialization of subcutaneous fascial flaps and muscle-only flaps in the oral cavity. A rabbit model. Int J Oral Maxillofac Surg 27:141, 1998.

6.Walden JL, Garcia H, Hawkins H, et al.: Both dermal matrix and epidermis contribute to an inhibition of wound contraction. Ann Plast Surg. 45:162, 2000.

7.Uehara M, Helman JI, Lillie JH, et al.: Blood supply to the platysma muscle flap: an anatomic study with clinical correlation. J Oral Maxillofac Surg 59:642, 2001.

8.Hill MW, Mackenzie IC: The influence of differing connective tissue substrates on the maintenance of adult stratified squamous epithelia. Cell Tissue Res 237:473, 1984.

9.Uitto J: Connective tissue biochemistry of the aging dermis. Age-related alterations in collagen and elastin. Dermatol Clin 4:433, 1986.

10. Leipziger LS, Glushko V, DiBernardo B, et al.: Dermal wound repair: role of collagen matrix implants and synthetic polymer dressings. J Am Acad Dermatol 12:409, 1985.

11.Li AK, Ehrlich HP, Trelstad RL, et al.: Differences in healing of skin wounds caused by burn and freeze injuries. Ann Surg 191:244, 1980.

12. Shiraiwa M, Goto T, Yoshinari M, et al.: A study of the initial attachment and subsequent behavior of rat oral epithelial cells cultured on titanium. J Periodontol 73:852, 2002. 


\section{Legends to figures}

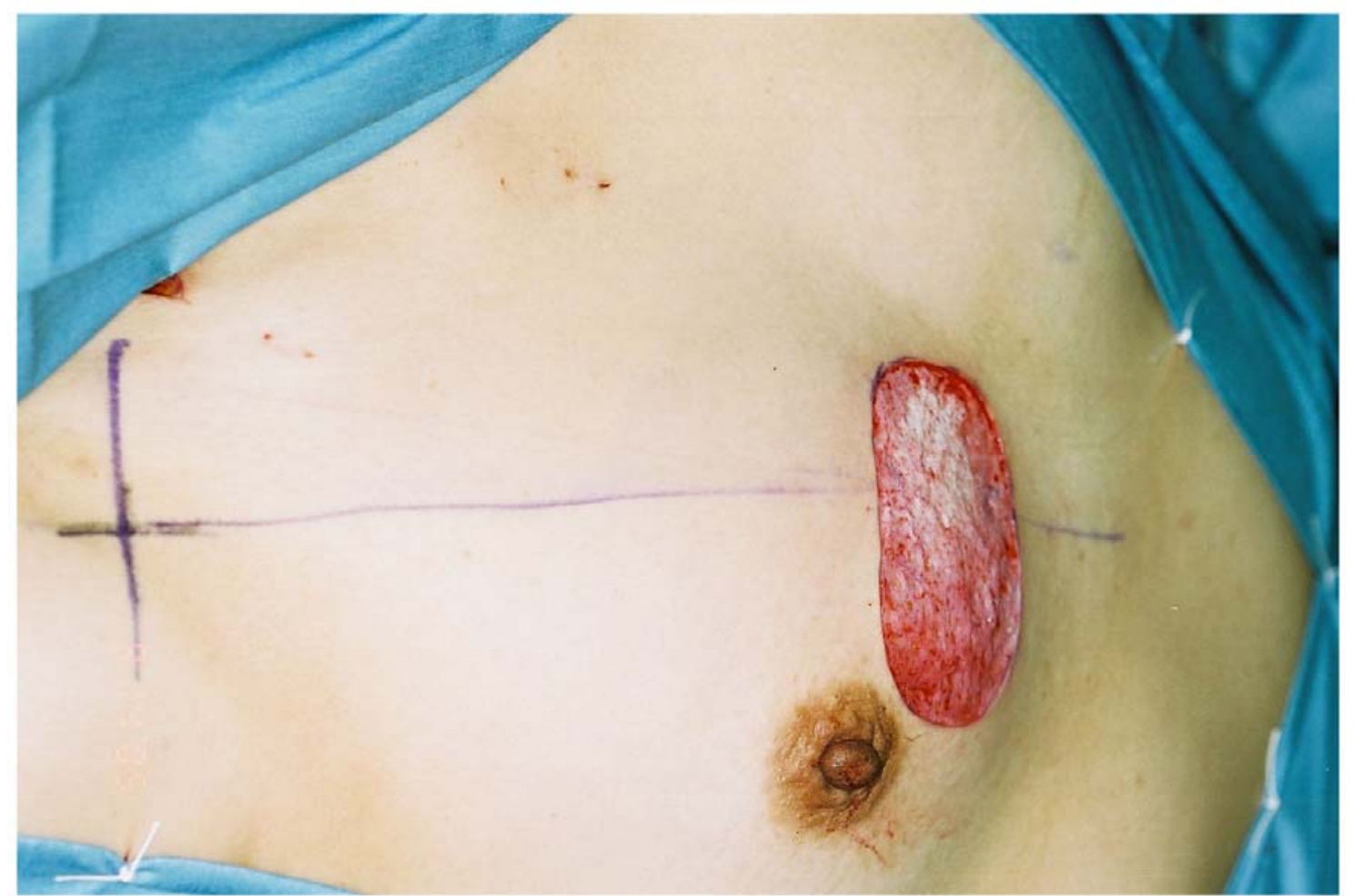

Fig. 1: Denuded skin paddle of pectoralis major myodermal flap (case 6). 


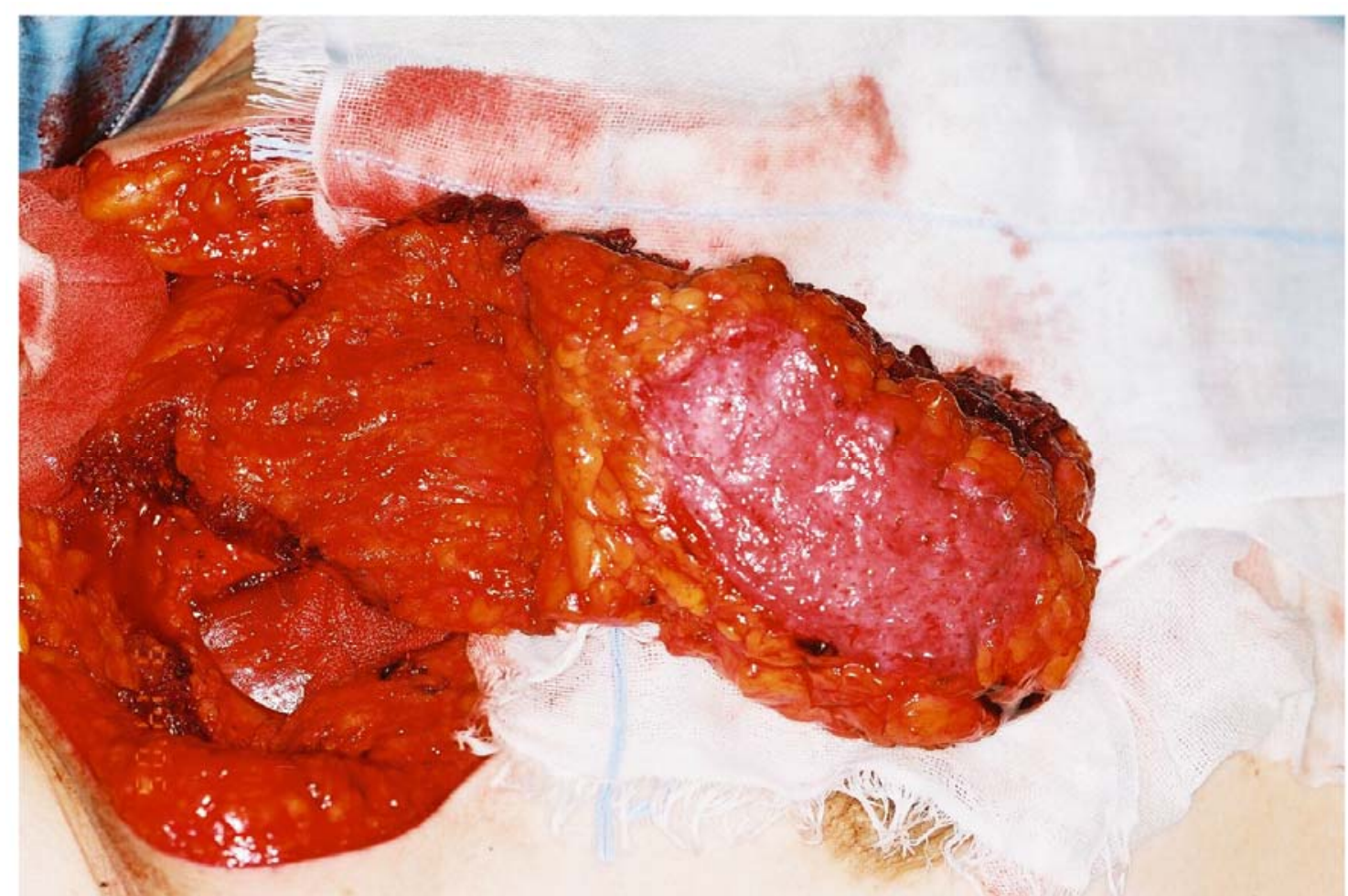

Fig. 2: Elevated pectoralis major myodermal flap (case 6). 


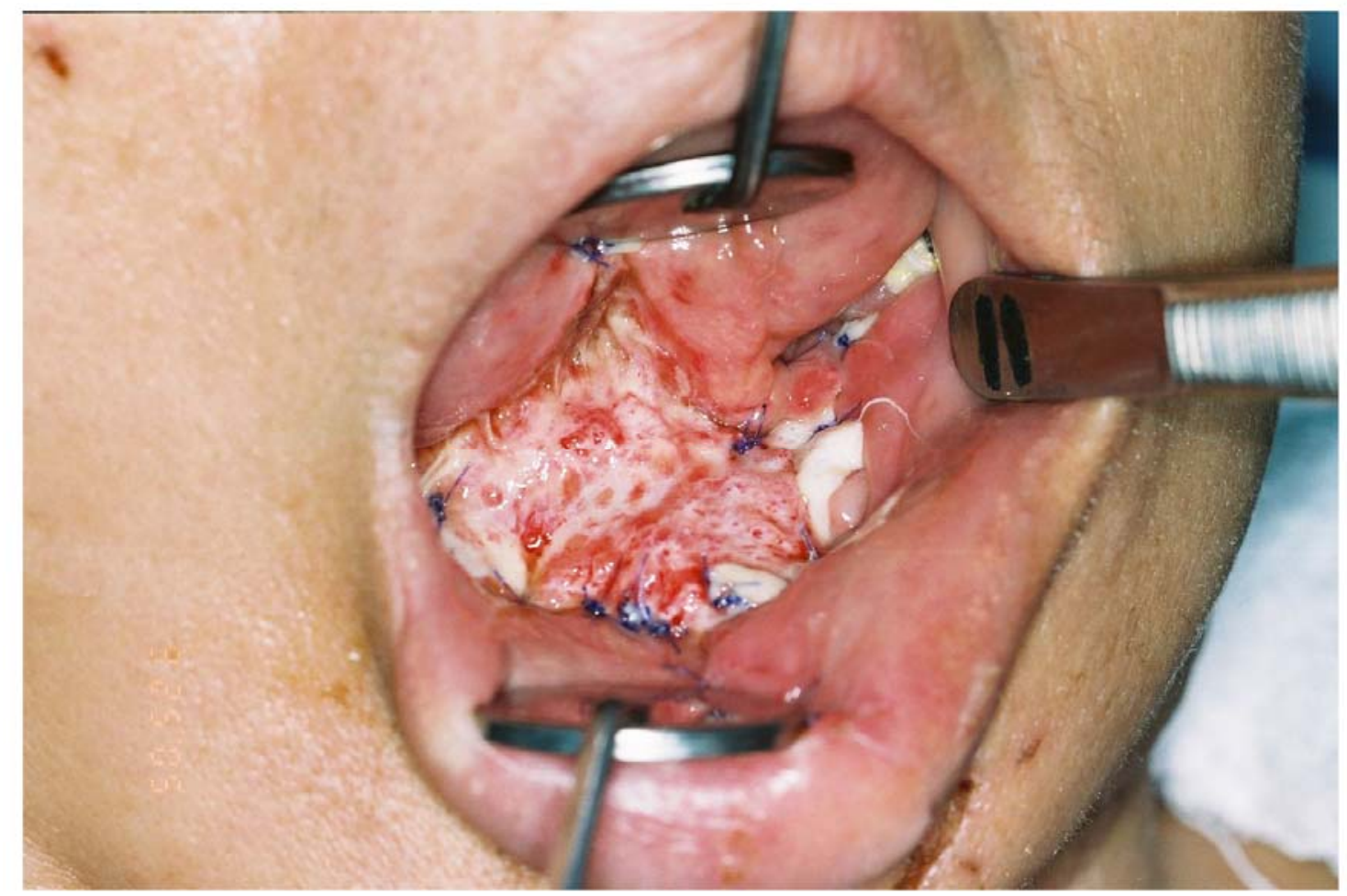

Fig. 3: Pectoralis major myodermal flap applied to a defect of the oral cavity (case 6). 


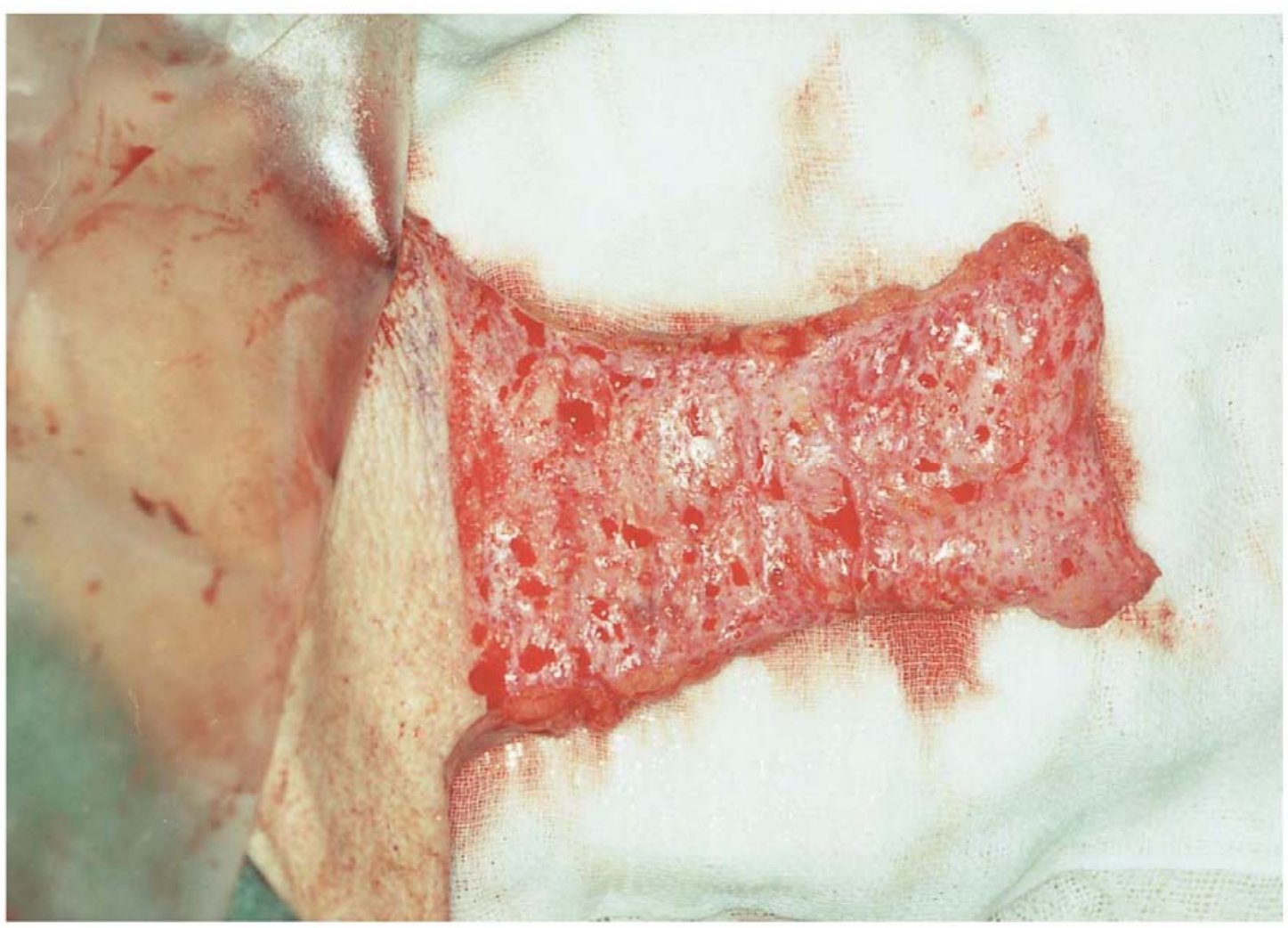

Fig. 4: Elevated platysma myodermal flap (case 3). 


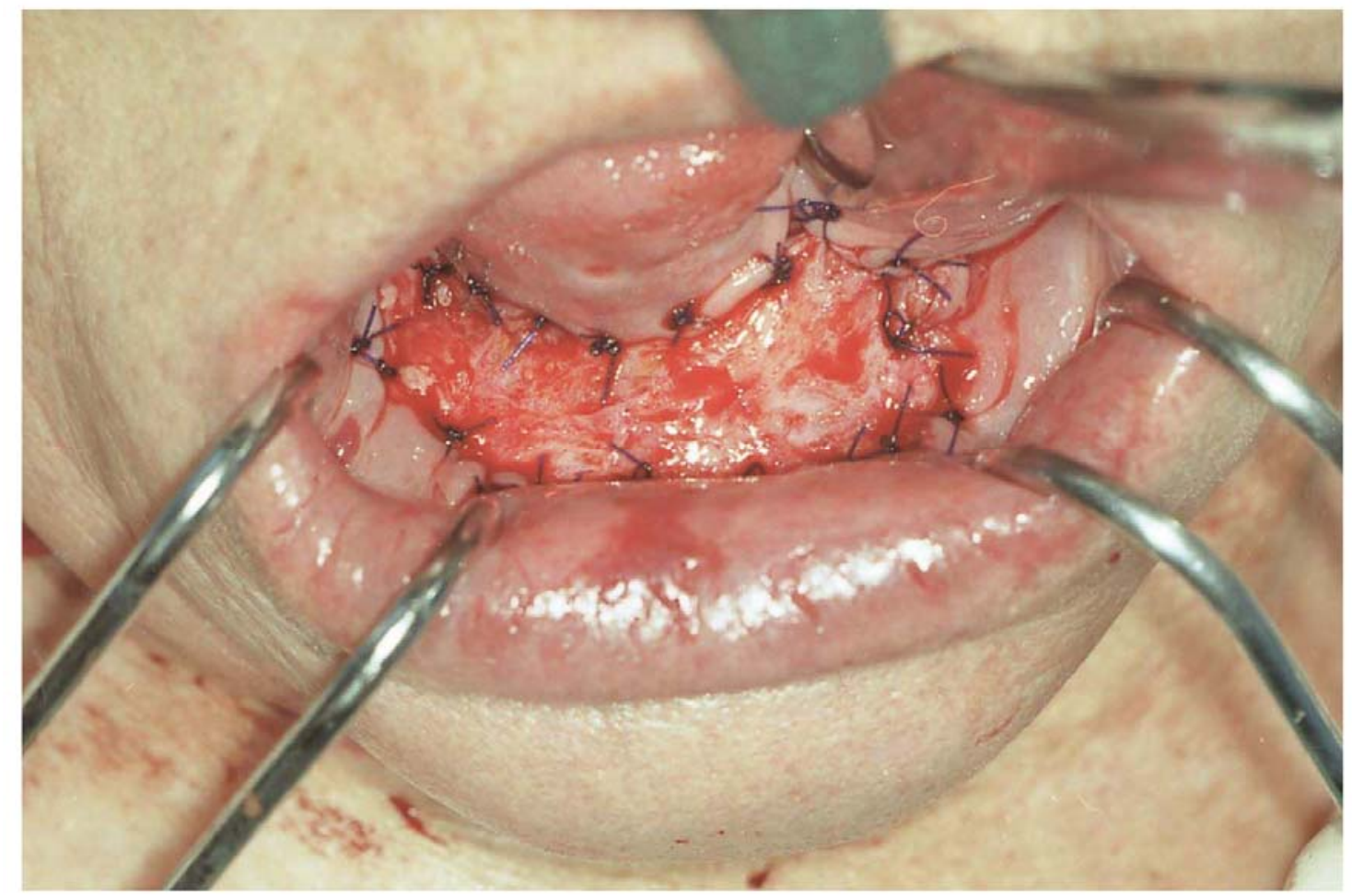

Fig. 5: Platysma myodermal flap applied to a defect of the oral cavity (case 3). 


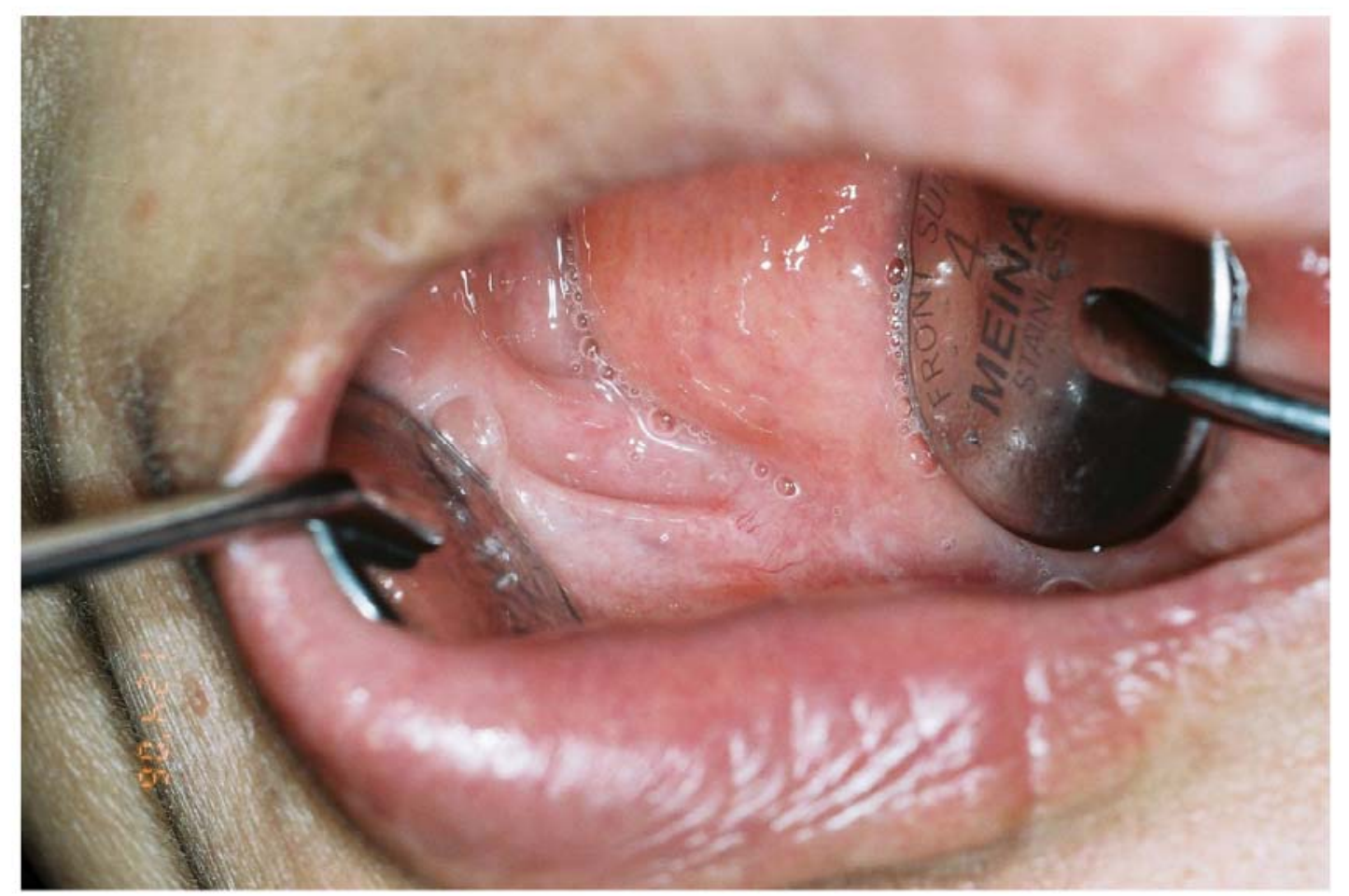

Fig. 6: Secondarily epithelialized pectoralis major myodermal flap, 4 months after the operation (case 6). 


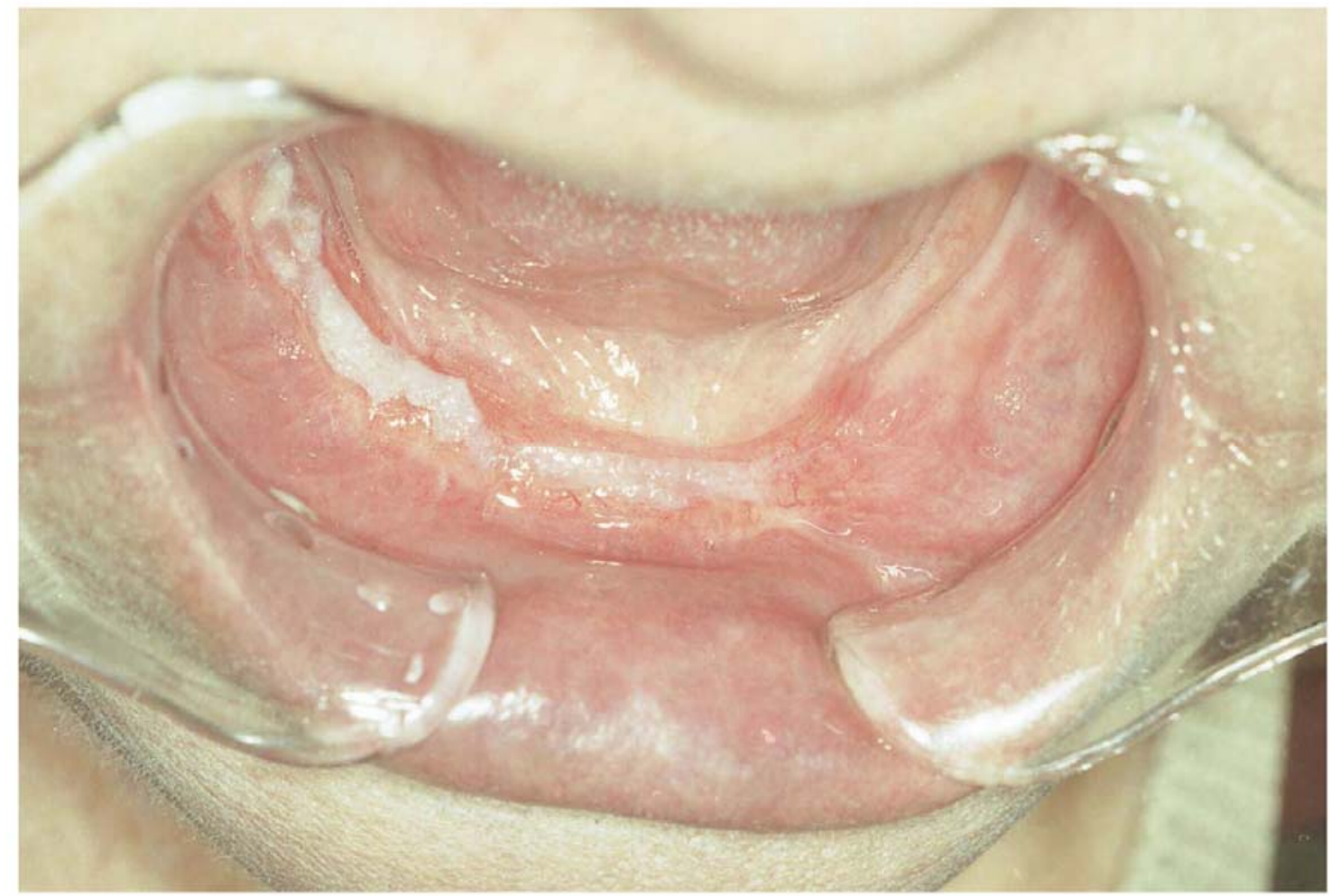

Fig. 7: Secondarily epithelialized platysma myodermal flap, 2 months after the operation (case 3). Mild contraction was observed. 


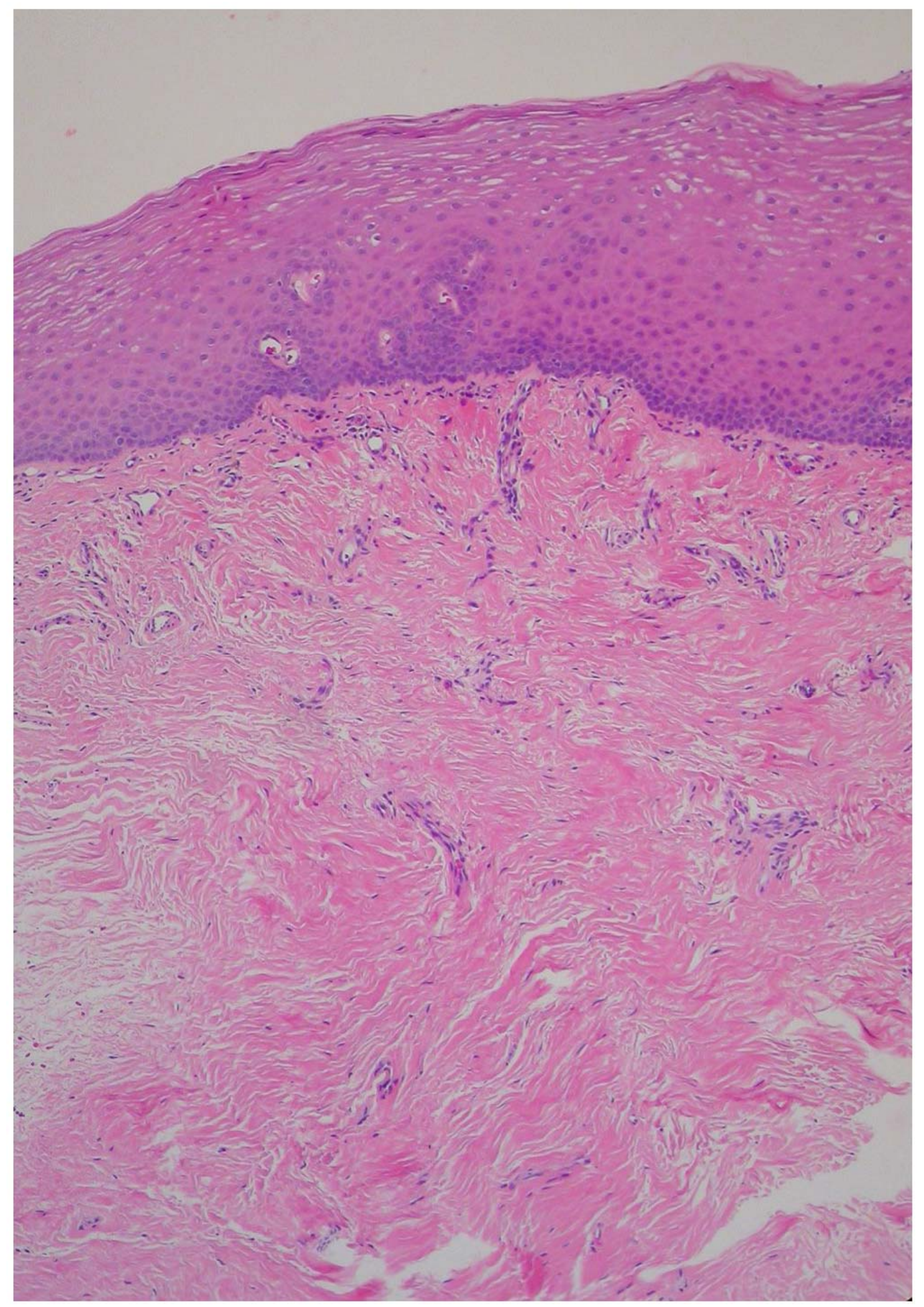

Fig. 8: Biopsy of 3 years postoperation (Hematoxylin and Eosin stain, $\mathrm{x}$ 30) (case 3). Epithelium over the collagenous layer is shown. 